\title{
Early pregnancy weight gain and fat accrual predict pregnancy outcome in growing adolescent sheep
}

\author{
Jacqueline M Wallace, John S Milne and Raymond P Aitken \\ Rowett Institute, University of Aberdeen, Aberdeen, UK \\ Correspondence should be addressed to J M Wallace; Email: jacqueline.wallace@abdn.ac.uk
}

\begin{abstract}
The competition for nutrients when pregnancy coincides with continuing growth in biologically immature adolescent girls increases their risk of preterm delivery and low birthweight and is partly replicated in the overnourished adolescent sheep paradigm. Although overfeeding to promote rapid maternal growth robustly leads to a reduction in average birthweight relative to slow-growing controlfed adolescents of equivalent age, the extent of prenatal compromise is variable. This retrospective analysis of a large cohort of identically managed pregnancies determined whether maternal anthropometry predicts the severity of fetal growth-restriction (FGR) in growing adolescents. Singleton pregnancies were established by embryo transfer in adolescents subsequently control-fed $(n=96)$ or overnourished. The latter pregnancies were classified as non-FGR $(n=116)$ or FGR $(n=96)$ if lamb birthweight was above or below the optimally fed control mean minus 2SD. A similar approach categorised placental growth-restriction (PIGR) and preterm delivery. Gestation length, placental mass and lamb birthweight were FGR $<$ non-FGR $<$ control (post hoc $P<0.01$ ). Relative to the non-FGR group, overnourished dams with FGR were marginally leaner and lighter at conception $(P=0.023 / P=0.014)$ and had greater gestational weight gain (GWG) during the first-third of pregnancy $(P<0.001)$. GWG during this early period was also higher in PIGR compared with non-PIGR, and in very preterm vs term deliveries $(P<0.01)$. Likewise maternal leptin concentrations (fat accrual biomarker) were FGR $>$ non-FGR by day 60 , and changes in leptin throughout pregnancy predicted attenuated fetal cotyledon mass and birthweight $(P=0.01$ to $<0.001)$. The anthropometric antecedents of FGR in still-growing adolescent sheep originate in early pregnancy coincident with early placental development.

Reproduction (2021) 161 227-238
\end{abstract}

\section{Introduction}

Becoming pregnant during adolescence is a wellestablished risk factor for adverse gestational outcome independent of geographical setting. The hazards are multiple and robustly include a greater likelihood of spontaneous miscarriage, preeclampsia, stillbirth, preterm delivery, low birthweight, neonatal and/or maternal mortality (Malabarey et al. 2012, Kozuki et al. 2013, Ganchimeg et al. 2014, Azevedo et al. 2015, Neal et al. 2016, Paul 2018, Marvin-Dowle \& Soltani 2020). The degree of risk is particularly high in very young girls (typically $<16$ years) who are more likely to be gynaecologically and biologically immature (CondeAgudelo et al. 2005, Salihu et al. 2006, Leppälahti et al. 2013, Torvie et al. 2015, Weng et al. 2014, Neal et al. 2018), and the effect on birthweight is exacerbated if maternal growth per se is deemed incomplete (Frisancho et al. 1985) or is ongoing during pregnancy (Scholl et al. 1997). Maternal anthropometric data from the latter prospective cohort is arguably the most accurate available as maternal growth status was defined on the basis of sequential changes in knee height over a 6-month period from mid-pregnancy to 4-6 weeks post-partum.
Girls who continued to grow comprised $\sim 50 \%$ of the pregnant population ( $\leq 16$ years) and were characterised by higher gestational weight-gains (GWG) and increased fat stores. Counterintuitively this was associated with a lower average birthweight and a three-fold greater risk of small-for-gestational-age delivery compared with non-growing adolescents of equivalent age, and mature women (Scholl et al. 1994, 1997). The effect on birthweight is attributed to a competition for nutrients whereby the mother's growth requirements take priority and conceptus growth is therefore compromised.

Our sheep model was originally developed to explore this alteration in nutrient partitioning in young biologically immature and still-growing adolescents. We deliberately choose to establish pregnancy using assisted conception procedures, involving adult ewe donor superovulation, embryo recovery and synchronous transfer, in order to avoid several of the known issues linked to attempting to breed adolescent sheep naturally, namely a variation in puberty onset, a transient first breeding season, failure to be mated, poor quality embryos and high embryo loss (Beck et al. 1996, Kenyon et al. 2014, Edwards et al. 2016). Most importantly our approach allowed us to nutritionally 
manipulate maternal growth-velocity in very young adolescents during a singleton pregnancy. Accordingly, when young adolescent dams were overnourished to promote rapid weight-gain and progressive fat accrual, conceptus development was impaired relative to slowgrowing optimally fed control adolescents of equivalent age. Placental development, uteroplacental blood flows and fetal nutrient supply were negatively impacted and premature delivery of low birthweight lambs followed (Wallace et al. 1996, 1997a, 2002, 2004, 2008). These adverse pregnancy outcomes in rapidly growing dams have proved consistent across multiple studies but the severity of prenatal growth-restriction within studies is variable in spite of an equivalent nutritional manipulation. As the placenta is the root cause of fetal growth-restriction in these pregnancies we hypothesised that subtle differences in maternal live-weight gain and fat accrual during the main period of placental growth may explain the severity of poor pregnancy outcome. In sheep the absolute growth rate of the placenta reaches a maximum near day 55, while the apex in placental mass occurs between days 75 and 80 of gestation (Ehrhardt \& Bell 1995), hence our focus was changed in maternal anthropometry spanning the first two-thirds of pregnancy. To test our hypothesis we used a dataset involving $>200$ overnourished adolescent pregnancies categorised as fetal growth-restricted (FGR) or otherwise, and compared them with 100 optimally fed controls.

While external assessment of subcutaneous fat level by body condition scoring is a useful tool for noninvasively assessing adiposity in sheep it is known to be less sensitive mid-scale (Miller et al. 2018) and may lack precision in growing adolescents where lean tissue growth is the initial dominant nutrient partitioning priority. Moreover, it tells us little about fat accumulation at other potentially important central sites within the body. In contrast, peripheral leptin concentrations reflect the overall quantity of adipose tissue throughout the animal and we have previously reported strong positive correlations between circulating leptin and body-fat percentage measured by dual energy X-ray absorptiometry in growing non-pregnant adolescents (Wallace et al. 2020). Thus we further postulate that changes in leptin concentrations in pregnant adolescents may provide a sensitive biomarker of relative differences in maternal fat accrual with the potential to predict the extent of placental and fetal growth-restriction. To test this we used a subgroup of the main cohort involving 55 overnourished and 18 control pregnancies.

\section{Methods}

\section{Pregnancy establishment in adolescent sheep}

Procedures were licensed under the UK Animals (Scientific Procedures) Act of 1986 and approved by the Rowett's Ethical Review Committee. Animals were housed under natural lighting conditions at $57^{\circ} \mathrm{N}, 2^{\circ} \mathrm{W}$ in individual open-wide bar pens that facilitated nose-to-nose interactions with adjacent animals. Pregnancies were established by assisted conception procedures precisely as detailed previously (Wallace et al. 2020). In brief, adult ewes (Border Leicester $\times$ Scottish Blackface) of known reproductive history (third or fourth parity), and in prime breeding condition (mean adiposity score 2.3 units) were superovulated and intrauterine inseminated to act as embryo donors. The resulting embryos were recovered on day 4 after insemination and grade 1 morula, optimum for stage, were synchronously transferred into the hormonally primed uteri of adolescent recipients (Dorset Horn $\times$ Greyface) to generate singleton pregnancies. Adults were preferentially used as embryo donors as earlier studies discovered that embryos from adolescent ewes have an innately low viability following transfer into either an adolescent or adult uterus (Quirke \& Hanrahan 1977, McMillan \& McDonald 1985). Within individual embryo transfer days, the embryos for any given donor ewe were distributed across study groups helping maximise the genetic homogeneity of the resulting conceptus units. The adolescent recipients were selected from a closed flock free from Enzootic abortion and vaccinated against Toxoplasmosis 6 weeks prior to breeding (Toxovax; Intervet UK Ltd.). Embryo transfers were carried out on 33 separate days in 5 different years during the first-half of the natural breeding season (mid-Nov to late-Dec) when the adolescents were $\sim 7.5$ months old, peripubertal, and had attained similar initial liveweight $(44.3 \pm 0.34 \mathrm{~kg})$ and adiposity score $(2.3 \pm 0.01)$. The latter is equivalent to $23 \%$ body fat (Russel et al. 1969), while bodyweight at conception equates to $\sim 70 \%$ of the mature bodyweight of primiparous ewes of equivalent genotype at 20 months of age. Approximately one-third of the animals were destined to become optimally fed controls while the remaining two-thirds were overnourished in the expectation that approximately half of the pregnancies would result in markedly growth-restricted lambs for ongoing developmental programming studies (Adam et al. 2011, Wallace et al. 2011, 2012, 2014, 2018, 2020).

\section{Nutritional management during pregnancy}

Commencing directly after embryo transfer, adolescent recipients were offered either a control or high level of a complete diet providing $12 \mathrm{MJ}$ of metabolisable energy (ME) and $140 \mathrm{~g}$ of crude protein per $\mathrm{kg}$. The diet contained $30 \%$ coarsely milled hay, $41.5 \%$ barley $17.5 \%$ Hipro soya, $10 \%$ molasses, $0.35 \%$ salt, $0.25 \%$ limestone, $0.25 \%$ dicalcium phosphate and $0.15 \%$ of a vitamin-mineral mix and was prepared as required on-site (Wallace et al. 2006). Fresh food was offered twicedaily at 08:00 $\mathrm{h}$ and 16:00 $\mathrm{h}$. For the optimally fed controls the dietary level was calculated to preserve the original adiposity level throughout pregnancy and to provide $100 \%$ of the estimated ME and protein requirements of the adolescent sheep carrying a singleton fetus according to the stage of pregnancy. Practically this is achieved via a target gestational weight-gain of $75 \mathrm{~g}$ per day for the first two-thirds of gestation followed by individual weekly stepwise increases in rations to meet the evolving nutrient needs of the fetus during the finalthird of pregnancy. This facilitates a small degree of maternal growth over the course of the entire pregnancy. In contrast, 
the high ration was fed ad libitum throughout pregnancy. To achieve this rations were increased stepwise over a 10-14 day period until the daily food refusal was $\sim 15 \%$ of the amount offered and adjusted twice-weekly thereafter to maintain the daily refusal at this target level. These animals were considered overnourished $(\sim 2.25 \times$ control intakes for the first two-thirds of gestation and $\sim 1.7 \times$ control intakes thereafter). To facilitate this accurate nutritional management external adiposity score, assessed by a single operator throughout, was measured at $\sim$ monthly intervals during the first two-thirds of pregnancy and fortnightly during the final-third. Maternal weight was recorded immediately prior to embryo transfer, and at regular intervals during the first two-thirds of pregnancy. In all cases, weight data were available at $27 \pm 0.2,50 \pm 0.2,75 \pm 0.1$ and $95 \pm 0.2$ days of gestation (mean \pm S.E.M.). A final pre-delivery weight was measured at day $133 \pm 0.1$.

\section{Perinatal management, lambing and neonatal measurements}

As overnourished adolescent dams consistently deliver early, all ewes were supervised $24 \mathrm{~h}$ per day during the expected delivery period from day 135 of gestation to the last control birth on day 150. Ewes were allowed to spontaneously labour and lambing assistance matched requirement. After delivery lambs were dried, weighed and girth at the umbilicus measured. Oxytocin (10iu, Intervet UK Ltd.) was administered i.v. to induce milk let-down and the udder stripped by hand to determine the initial colostrum yield. The colostrum was fed back to the lamb by bottle or feeding tube. Where colostrum yield was less than the required $50 \mathrm{~cm}^{3}$ per $\mathrm{kg}$ birthweight, supplementary colostrum from a frozen donor pool was used. Following delivery of the fetal component of the placenta, it was laid out on a tray, replicating the orientation in vivo to check that it was intact, and the fetal cotyledons were then dissected from the membranes and their total weight recorded. Membrane plus cotyledon weight was also recorded (placental weight). Seven ewes either retained the placenta entirely (4 overnourished) or ate part of it before it could be retrieved from the pen ( 1 control, 2 overnourished). Data pertaining to these individual pregnancies has been excluded leaving full maternal anthropometry, lamb and placenta weight records for 96 control and 212 overnourished pregnancies.

\section{Plasma leptin analysis}

In a subgroup of the above pregnancies (18 control, 55 overnourished), maternal venous blood samples were collected at $\sim 12$ noon on day $0,30,60,90$ and 130 of gestation and the resulting plasma analysed for leptin in duplicate (Marie et al. 2001). The lower limit of detection was $0.1 \mathrm{ng}$ leptin/mL, and the inter and intra-assay coefficients of variation were $<8 \%$.

\section{Definitions and data analysis}

Data were analysed using Minitab (version 19; Minitab Inc., State College, PA). Normality was confirmed and there was no evidence of outliers for indices of maternal anthropometry or pregnancy outcome parameters using Grubbs' testing at $5 \%$ significance. Prenatal growth-restriction and preterm delivery categories were defined using the mean and S.D. for optimal control deliveries. Control birthweight and placental weight were not impacted by year of study $(P=0.304$ and 0.822 , respectively). As control males were heavier than their female counterparts (mean \pm S.D.: $5607 \pm 717 \mathrm{~g}$ vs $5291 \pm 746 \mathrm{~g}$, respectively, $P=0.037$ ), FGR was defined on a sex-specific basis, and defined as such when birthweight in an overnourished pregnancy was less than the control mean minus 2 SD's, thus $<4173 \mathrm{~g}$ for males and $<3799$ $\mathrm{g}$ for females. The remaining overnourished pregnancies were categorised as non-FGR. A similar approach was used to define placental (cotyledon) growth-restriction. Again the control male total cotyledon weight at delivery was slightly heavier than the female (mean \pm S.D.: $156 \pm 46.1$ vs $138 \pm 39.9 \mathrm{~g}$, respectively, $P=0.05)$ and placental growth-restriction (PIGR) was defined using the sex-specific control mean minus 1.75 SD's, thus $<74.5 \mathrm{~g}$ for males and $<68.2 \mathrm{~g}$ for females. A total fetal cotyledon weight above these cut-offs was categorised as non-PIGR. The choice of cut-off in this instance reflected the much greater variance in total cotyledon weight in control pregnancies of both sexes. Gestation length was independent of sex and was $145.2 \pm 1.73$ days (mean \pm S.D.) for controls. Pregnancies were classified as preterm or very preterm delivery if gestation length was less than two or four SD's below the mean control gestation length, respectively, that is, 140-142 days for preterm and $\leq 139$ days for very preterm.

Maternal anthropometric and pregnancy outcome data for the three groups (control, non-FGR and FGR) were compared by ANOVA and post hoc comparisons used Fishers LSD method at $1 \%$ (Table 1). Within the overnourished pregnancies ANOVA was also used to separately compare non-FGR with FGR (Table 1), non-PIGR with PIGR (Fig. 1C), and early with term delivery (Fig. 1D). Categorical data were analysed by Fisher's exact test. Multiple regression was used to further interrogate the relationship between indices of maternal anthropometry and key pregnancy outcomes for the cohort as a whole. The former indices included weight and adiposity at baseline, GWG and changes in adiposity score between defined stages during the first two-thirds of gestation, and for pregnancy overall. The same approach was applied to the subgroup where maternal leptin concentrations were determined and confined to the overnourished animals only. In both cases best sets regression was used to identify which aspects could be reasonably omitted to keep the models simple and the predictors retained are detailed in Tables 2 and 3.

Maternal plasma leptin profiles were also analysed by a mixed-effects repeated-measures model with maternal ID as a random factor and gestational age and prenatal growth category (control, non-FGR and FGR) as fixed factors in the model together with their interaction (Fig. 2A). Post hoc comparison between groups at all stages of gestation was by Fishers LSD method. Pearson product-moment correlation analysis was used to explore relationships between variables where indicated and data are presented as correlation coefficients $(r)$. 
Table 1 Maternal anthropometry and pregnancy outcome in adolescent sheep offered an optimum control intake $(n=96)$ or overnourished $(n$ $=212$ ) throughout gestation and categorised according to fetal growth status after spontaneous delivery. ${ }^{*}$ Values are presented as mean \pm S.E.M.

\begin{tabular}{|c|c|c|c|c|c|}
\hline \multirow[b]{2}{*}{ Lamb growth category $\beta$} & \multirow{2}{*}{$\begin{array}{l}\text { Control } \\
\text { Normal } \\
\end{array}$} & \multirow{2}{*}{$\begin{array}{c}\text { Overnourished } \\
\text { Non-FGR } \\
\end{array}$} & \multirow{2}{*}{$\begin{array}{c}\text { Overnourished } \\
\text { FGR } \\
\end{array}$} & \multicolumn{2}{|c|}{$P$-value } \\
\hline & & & & $\begin{array}{c}\text { Normal vs } \\
\text { Non-FGR vs } \\
\text { FGR }\end{array}$ & $\begin{array}{c}\text { Non-FGR } \\
\text { vs FGR }\end{array}$ \\
\hline Male:female & $45: 51$ & $58: 58$ & $55: 41$ & 0.331 & 0.289 \\
\hline Wt. at conception (kg) & $44.2 \pm 0.39^{\mathrm{ab}}$ & $45.3 \pm 0.64^{\mathrm{a}}$ & $43.0 \pm 0.63^{b}$ & 0.022 & 0.014 \\
\hline GWG, ET to day 50 (g/day) & $48 \pm 3.2^{\mathrm{a}}$ & $254 \pm 6.0^{b}$ & $286 \pm 6.4^{c}$ & $<0.001$ & $<0.001$ \\
\hline GWG, days 50-95 (g/day) & $109 \pm 2.9^{\mathrm{a}}$ & $315 \pm 5.4^{\mathrm{b}}$ & $319 \pm 6.3^{b}$ & $<0.001$ & 0.655 \\
\hline GWG, ET to day 95 (g/day) & $76 \pm 2.3^{\mathrm{a}}$ & $283 \pm 4.6^{b}$ & $302 \pm 4.9^{c}$ & $<0.001$ & 0.006 \\
\hline Weight pre-delivery, day $133(\mathrm{~kg})$ & $62.2 \pm 0.39^{\mathrm{a}}$ & $84.7 \pm 0.65^{b}$ & $81.9 \pm 0.72^{c}$ & $<0.001$ & 0.004 \\
\hline Adiposity at conception* & $2.3 \pm 0.01$ & $2.3 \pm 0.02$ & $2.3 \pm 0.03$ & 0.028 & 0.023 \\
\hline$\Delta$ adiposity, ET to day 50 & $0 \pm 0^{a}$ & $0.2 \pm 0.01^{b}$ & $0.2 \pm 0.02^{b}$ & $<0.001$ & 0.079 \\
\hline$\Delta$ adiposity, days 50-95 & $0 \pm 0^{\mathrm{a}}$ & $0.3 \pm 0.01^{b}$ & $0.3 \pm 0.02^{b}$ & $<0.001$ & 0.808 \\
\hline$\Delta$ adiposity, ET to day 95 & $0 \pm 0^{\mathrm{a}}$ & $0.6 \pm 0.02^{b}$ & $0.6 \pm 0.02^{b}$ & $<0.001$ & 0.204 \\
\hline Adiposity pre-delivery & $2.3 \pm 0.01^{\mathrm{a}}$ & $3.2 \pm 0.02^{\mathrm{b}}$ & $3.1 \pm 0.03^{b}$ & $<0.001$ & 0.335 \\
\hline Gestation length (days) & $145.2 \pm 0.18^{a}$ & $141.6 \pm 0.18^{b}$ & $140.8 \pm 0.23^{c}$ & $<0.001$ & 0.004 \\
\hline Preterm delivery, $n(\%)^{¥}$ & $3(3.1 \%)^{\mathrm{a}}$ & $66(56.9 \%)^{b}$ & $50(52.1 \%)^{b}$ & $<0.001$ & 0.483 \\
\hline Very preterm delivery, $n(\%)^{*}$ & $0(0 \%)^{a}$ & $15(12.9 \%)^{b}$ & $26(27.1 \%)^{\mathrm{c}}$ & $<0.001$ & 0.009 \\
\hline Sex ratio for early deliveries & $1 \mathrm{M}, 2 \mathrm{~F}$ & $37 \mathrm{M}, 44 \mathrm{~F}$ & $41 \mathrm{M}, 35 \mathrm{~F}$ & 0.500 & 0.300 \\
\hline Birth weight $(\mathrm{g})$ & $5439 \pm 76^{a}$ & $4787 \pm 56^{b}$ & $3044 \pm 69^{c}$ & $<0.001$ & $<0.001$ \\
\hline Adjusted birth weight $(\mathrm{g})^{\mathrm{r}}$ & $5416 \pm 72^{\mathrm{a}}$ & $5007 \pm 55^{b}$ & $3205 \pm 70^{c}$ & $<0.001$ & $<0.001$ \\
\hline Girth at umbilicus (mm) & $40.1 \pm 0.31^{\mathrm{a}}$ & $39.1 \pm 0.23^{\mathrm{a}}$ & $33.0 \pm 0.37^{b}$ & $<0.001$ & $<0.001$ \\
\hline Placental weight (g) & $442 \pm 11.5^{\mathrm{a}}$ & $369 \pm 8.7^{b}$ & $241 \pm 6.3^{c}$ & $<0.001$ & $<0.001$ \\
\hline Fetal cotyledon weight (g) & $146.3 \pm 4.4^{\mathrm{a}}$ & $101.8 \pm 2.7^{b}$ & $61.5 \pm 2.1^{\mathrm{c}}$ & $<0.001$ & $<0.001$ \\
\hline §Placental growth-restriction, $n(\%)$ & $0(\%)^{\mathrm{a}}$ & $14(12.1 \%)^{b}$ & $71(74.0 \%)^{c}$ & $<0.001$ & $<0.001$ \\
\hline $\begin{array}{l}\text { Sex ratio for placental growth- } \\
\text { restriction }\end{array}$ & $\mathrm{n} / \mathrm{a}$ & $9 \mathrm{M}, 5 \mathrm{~F}$ & $38 \mathrm{M}, 33 \mathrm{~F}$ & $\mathrm{n} / \mathrm{a}$ & 0.563 \\
\hline Colostrum yield (mL) & $492 \pm 39.8^{\mathrm{a}}$ & $202 \pm 13.6^{b}$ & $116 \pm 10.4^{\mathrm{c}}$ & $<0.001$ & $<0.001$ \\
\hline $\begin{array}{l}\text { No. with inadequate } \\
\text { colostrum } / \mathrm{kg} \text { fetus }^{\alpha}\end{array}$ & 24 of $90^{\mathrm{a}}$ & 76 of $116^{b}$ & 60 of $87^{b}$ & $<0.001$ & 0.605 \\
\hline Birth wt: cotyledon wt & $39.6 \pm 1.00^{\mathrm{a}}$ & $49.9 \pm 1.15^{b}$ & $52.1 \pm 1.13^{b}$ & $<0.001$ & 0.162 \\
\hline $\begin{array}{l}\text { Birth wt: Maternal wt } \\
\text { gain ET to d } 95\end{array}$ & $863 \pm 40.2^{\mathrm{a}}$ & $184 \pm 4.3^{b}$ & $110 \pm 3.4^{b}$ & $<0.001$ & $<0.001$ \\
\hline $\begin{array}{l}\text { Cotyledon wt: Maternal wt } \\
\text { gain ET to d } 95\end{array}$ & $23.5 \pm 1.34^{\mathrm{a}}$ & $3.9 \pm 0.14^{b}$ & $2.2 \pm 0.09^{b}$ & $<0.001$ & $<0.001$ \\
\hline
\end{tabular}

Three-way comparison by ANOVA followed by Fishers LSD method. Within rows where superscripts differ, $P<0.01$. Categorical data by Fisher's exact test. Statistically significant $P$ values are highlighted in bold.

${ }^{\beta}$ Lambs from overnourished dams were classified as fetal growth restricted (FGR) if birthweight was less than two s.D. below the mean sexspecific birthweight of the optimally nourished control group, that is, $<3799 \mathrm{~g}$ for females and $<4173 \mathrm{~g}$ for males. *Based on external body condition score (5-point scale where $1=$ emaciated and $5=$ morbidly obese, Russell et al. 1969) and assessed by a single operator throughout. ${ }^{\ddagger}$ Classified as preterm or very preterm delivery if gestation length was less than two or four s.D. below the mean control gestation length, respectively, that is, 140-142 days for preterm and $\leq 139$ days for very preterm. ${ }^{\Upsilon}$ Individually adjusted to a standard gestation length of 145 days

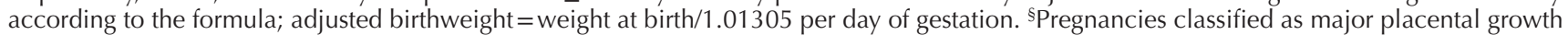
restriction (PIGR) if total fetal cotyledon weight was less than $1.75 \times$ s.D. below the mean sex-specific cotyledon weight of the optimally nourished control group, that is, $<68.2 \mathrm{~g}$ for females and $<74.5 \mathrm{~g}$ for males. ${ }^{\alpha}$ Defined based on requirement of $50 \mathrm{~mL} / \mathrm{kg}$ fetal weight, missing data for 6 control, 7 non-FGR and 3 FGR pregnancies.

$\mathrm{ET}$, single embryo transfer at day 4; GWG, gestational weight gain.

\section{Results}

\section{Maternal anthropometry and pregnancy outcome}

By design target GWG during the first two-thirds of pregnancy was achieved and the optimally nourished control adolescent dams maintained their initial adiposity score from embryo transfer until the final assessment prior to delivery (Table 1). Ninety-seven percent of the control lambs were spontaneously delivered at term ( $\geq 143$ days) and average gestation length equated the norm for this genotype and maternal age, namely 145 days (Wallace et al. 2004). Lamb birthweights in the control group ranged from 3830 to $7650 \mathrm{~g}$ and were considered normal as none were classified as FGR using the approach specified in the data analysis section. Similarly placental mass and fetal cotyledon weight in controls provide the optimum growth bench-mark for this genotype (Table 1 ), and both were positively related to lamb birthweight $(r=0.656$ and $r=0.589, n=96, P<0.001)$. Relative to these optimally fed controls and independent of lamb sex, $\sim 45 \%$ of overnourished pregnancies were categorised as markedly growth-restricted (FGR): this equated to an average reduction in placental mass, fetal cotyledon weight and lamb birthweight of 55, 58 and 44\%, respectively. Placental mass and fetal cotyledon weight 

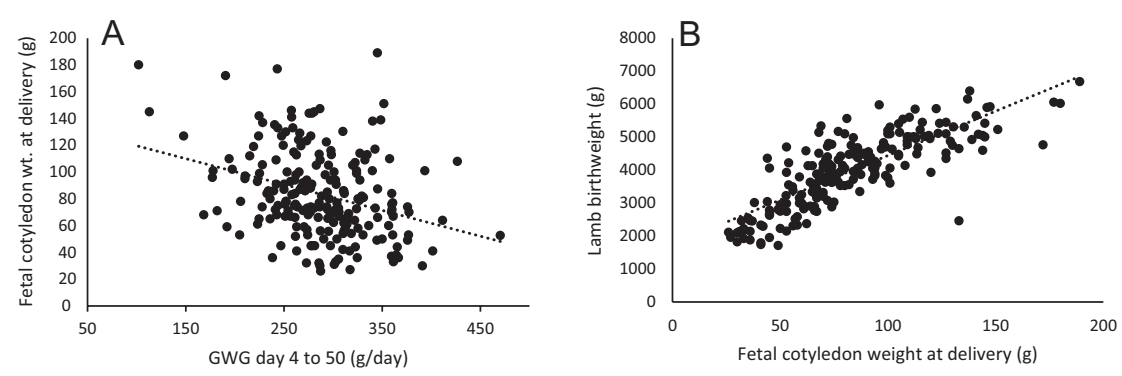

Figure 1 Relationship between (A) gestational weight gain during early pregnancy and fetal cotyledon weight at delivery, $r=-0.319, P<$ 0.001 , and between (B) fetal cotyledon weight and lamb weight at birth, $r=0.804, P<0.001$ in overnourished adolescent pregnancies $(n=$ 212). Gestational weight gain (GWG) of overnourished dams per defined period in early to mid-gestation is shown in relation to
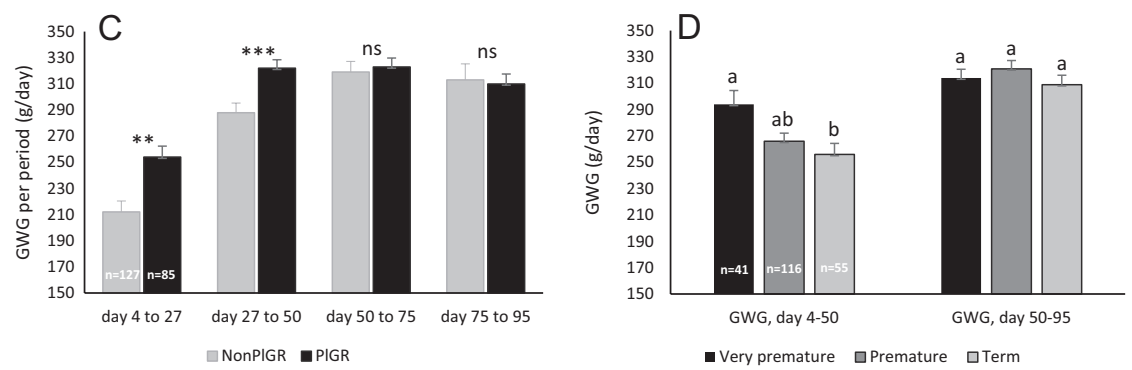
whether $(C)$ the placenta was categorised as growth-restricted (PIGR) or non-PIGR and (D) the delivery was categorised as very premature ( $\leq 139$ days), premature (140-142 days) or term ( $\geq 143$ days). In (C) ${ }^{* *} P=0.002,{ }^{* * *} P=$ $0.001, \mathrm{~ns}=$ not significant, and in (D) for GWG in early pregnancy the overall effect of delivery category was $P=0.016$ and where superscript letters differ categories differ at $P<0.01$.

were positively associated with lamb birthweight $(r=0.772$ and $r=0.701, n=96, P<0.001)$, and $75 \%$ of the placentae were defined as markedly growthrestricted (PIGR), based on fetal cotyledon weight. In contrast the remaining overnourished pregnancies (nonFGR) were much less perturbed but average placental mass, fetal cotyledon weight and lamb birthweight were nonetheless lower than in controls $(17,30$ and $12 \%$, respectively, $P<0.01)$. Only $11 \%$ were defined as PIGR and placental mass and fetal cotyledon weight were again positively associated with lamb birthweight $(r=0.691$ and $0.644, n=116, P<0.001)$. The differences in lamb weight remained even after adjusting birthweight to a standard gestation length of 145 days. This adjustment is relevant as two-thirds of overnourished adolescent dams delivered early. The proportion of overnourished pregnancies with preterm delivery at 140-142 days was independent of prenatal growth-category $(P=0.487)$ but there was a greater incidence of very preterm delivery ( $\leq 139$ days) in the FGR compared with the non-FGR group $(P=0.009)$. Males were heavier than females in both prenatal growth categories (FGR: $3213 \pm 95$ vs $2817 \pm 89 \mathrm{~g}, P=0.004$, non-FGR: $5038 \pm 76$ vs $4535 \pm 68 \mathrm{~g}, P<0.001)$ but there was no sex difference in the incidence of preterm or very preterm delivery (combined sex ratio shown in Table 1). Colostrum yield immediately after delivery was impacted by gestational intake (control > overnourished) and prenatal growth status (non-FGR > FGR). A similarly high proportion of overnourished dams in the FGR and non-FGR groups failed to produce sufficient colostrum to meet the initial lamb requirement of $50 \mathrm{~cm}^{3}$ per $\mathrm{kg}$ birthweight.

With respect to maternal anthropometry in the overnourished dams, the recipients that conceived and went on to have an FGR pregnancy were slightly lighter $(P=0.014)$ and leaner $(P=0.023)$ at the point of embryo transfer than the non-FGR group. Thereafter GWG was higher during the first-third of gestation in the FGR dams $(P<0.001$, Table 1$)$, equivalent during midgestation, and higher over the course of the first twothirds of pregnancy overall $(P=0.006)$. Figure 1 depicts the inverse relationship between early pregnancy weight-gain and fetal cotyledon weight at delivery on an individual pregnancy basis for all overnourished pregnancies, and the positive relationship between fetal cotyledon mass and lamb birthweight. It also highlights, independent of lamb size, that the most perturbed overnourished pregnancies in terms of both placental

Table 2 Pregnancy weight gain as a predictor of gestation length, fetal cotyledon weight and birthweight at delivery in adolescent sheep $(n=308)$ carrying a single fetus.

\begin{tabular}{|c|c|c|c|c|c|c|}
\hline & \multicolumn{2}{|c|}{ Gestation length, days } & \multicolumn{2}{|c|}{ Fetal cotyledon weight, $g$} & \multicolumn{2}{|c|}{ Birthweight, g } \\
\hline & B coefficient (S.E.) & $P$-value & B coefficient (S.E.) & $P$-value & B coefficient (S.E.) & $P$-value \\
\hline Weight at ET & $-0.041(0.021)$ & 0.05 & $1.160(0.368)$ & 0.002 & $15.9(10.2)$ & 0.118 \\
\hline \multicolumn{7}{|c|}{ Gestational weigth gain, g/day } \\
\hline ET to Day 27 & $-0.005(0.001)$ & 0.001 & $-0.059(0.026)$ & 0.027 & $-1.525(0.832)$ & 0.038 \\
\hline Days $27-50$ & $-0.007(0.002)$ & $<0.001$ & $-0.104(0.028)$ & $<0.001$ & $-2.940(0.783)$ & $<0.001$ \\
\hline Days $50-75$ & $-0.005(0.001)$ & 0.001 & $-0.100(0.025)$ & $<0.001$ & $-2.112(0.685)$ & 0.002 \\
\hline Days $75-95$ & $-0.000(0.001)$ & 0.734 & $-0.005(0.021)$ & 0.818 & $0.351(0.576)$ & 0.543 \\
\hline
\end{tabular}

Weight in kg, gestational weight gain (GWG) g/day. Statistically significant $P$ values are highlighted in bold.

ET, embryo transfer at day 4. 
Table 3 Predictors of fetal cotyledon weight, birthweight at delivery, gestation length and colostrum yield in 55 overnourished adolescents.

\begin{tabular}{|c|c|c|c|c|c|c|c|c|}
\hline & \multicolumn{2}{|c|}{ Fetal cotyledon weight, g } & \multicolumn{2}{|c|}{ Birthweight, $g$} & \multicolumn{2}{|c|}{ Gestation length, days } & \multicolumn{2}{|c|}{ Colostrum yield, $g$} \\
\hline & B coefficient (S.E.) & $P$-value & B coefficient (S.E.) & $P$-value & B coefficient (S.E.) & $P$-value & B coefficient (S.E.) & $P$-value \\
\hline \multicolumn{9}{|l|}{$\Delta$ leptin, $n g / m L$} \\
\hline Days $0-30$ & $-3.93(1.27)$ & 0.003 & $-137.5(34.8)$ & $<0.001$ & $-0.100(0.061)$ & 0.111 & $-14.20(3.87)$ & 0.001 \\
\hline Days 30-60 & $-4.68(1.20)$ & $<0.001$ & $-185.1(33.1)$ & $<0.001$ & $-0.252(0.058)$ & $<0.001$ & $-9.52(3.74)$ & 0.014 \\
\hline Days 60-90 & $-3.66(1.36)$ & 0.010 & $-139.2(37.5)$ & 0.001 & $-0.076(0.066)$ & 0.257 & $-6.96(4.17)$ & 0.102 \\
\hline Days 90-130 & $-3.88(1.05)$ & 0.001 & $-125.8(29.0)$ & $<0.001$ & $-0.107(0.051)$ & 0.044 & $-7.00(3.28)$ & 0.038 \\
\hline \multicolumn{9}{|l|}{$\Delta$ adiposity score $1-5$} \\
\hline Days $0-49$ & $-187.5(52.8)$ & 0.001 & $-4120(1430)$ & 0.006 & $-10.92(2.39)$ & $<0.001$ & $-295(159)$ & 0.070 \\
\hline Days 49-96 & $-36.1(40.6)$ & 0.378 & $-1090(1070)$ & 0.314 & $-3.05(1.89)$ & 0.114 & $28(122)$ & 0.820 \\
\hline Days 96-132 & $-18.3(29.7)$ & 0.541 & $-756(784)$ & 0.340 & $-3.12(1.39)$ & 0.030 & $-110(95.2)$ & 0.254 \\
\hline Pregnancy wt gain, kg & $3.45(1.13)$ & 0.004 & $107.3(35.5)$ & 0.004 & $0.163(0.068)$ & 0.021 & $4.25(4.12)$ & 0.309 \\
\hline
\end{tabular}

wt, weight. Statistically significant $P$ values are highlighted in bold.

growth-restriction and very premature delivery have a relatively higher GWG during early but not midpregnancy. Similarly, the regression analysis for the adolescent cohort as a whole reveals that irrespective of nutritional treatment, GWG in the three discrete 25-day periods from conception to day 75 of gestation were all predictive of gestation length, placental mass and lamb birthweight, with the most pronounced effects between days 27 and 50 in all cases (Table 2). All GWG coefficients were negative indicating that the greater the weight-gain the more likely that the lamb would be delivered early and it's prenatal growth compromised. Further on a group basis, the lower fetal cotyledon and birthweight to maternal weight-gain ratios in the FGR compared with the non-FGR pregnancies $(P<0.001)$ exemplify that the adolescent dams that grow fastest during the first-half of pregnancy transfer a lower proportion of that gain to the developing conceptus (Table 1). Although colostrum yield at parturition was inversely associated with GWG during both early and mid-pregnancy for the cohort as a whole $(r=-0.501$ and $r=-0.479, n=308$, $P<0.001)$ no such relationship was evident within the overnourished dams specifically $(P>0.65)$.

\section{Maternal leptin as an index of fat accrual and predictor of pregnancy outcome}

Absolute maternal leptin concentrations at intervals throughout gestation in a representative subgroup of animals are shown in Fig. 2A. Leptin levels did not vary between conception and late gestation in controls (average birthweight $5596 \pm 131 \mathrm{~g}$ ) in keeping with the nutritional management designed to maintain their initial external adiposity score throughout. In contrast peripheral plasma leptin levels diverged from controls by day 30 of gestation in the overnourished dams, and those that went on to deliver FGR lambs (average birthweight $3149 \pm 157 \mathrm{~g}, n=29$ ) had higher concentrations by day 60 of gestation and thereafter compared with the nonFGR group (average birthweight $5060 \pm 129 \mathrm{~g}, n=26$ ). Figure $2 \mathrm{~B}$ highlights the inverse relationship between delta maternal leptin concentrations across gestation and lamb birthweight. This association was very weak in control dams $(P=0.05)$ but marked in those who were overnourished $(P<0.001)$. For the latter, a multiple regression model was used to further assess the predictive value of changes in maternal leptin and anthropometry and the main pregnancy outcomes. As detailed in Table 3 , delta maternal leptin between all stages of gestation were predictive of both fetal cotyledon mass and birthweight at delivery, with the strongest relationships evident for the change in leptin between days 30 and 60, and between days 90 and 130 of gestation. The change in external adiposity score during the first but not the second or final-third of pregnancy was also strongly associated with these pregnancy outcomes. Similar but less pronounced relationships were evident for gestation length and in this instance it was delta leptin between days 30 and 60 and the change in adiposity during the firstthird of pregnancy that had the most pronounced effect. For colostrum yield at parturition there was a significant impact of changes in leptin in three of four gestational periods but in this instance the delta external adiposity during the first-third of pregnancy did not achieve formal significance $(P=0.07)$. All the aforementioned relationships had negative coefficients indicating that the greater this biomarker of fat accrual then the more likely that the pregnancy would be compromised. In contrast the coefficient for total pregnancy weight-gain, measured between conception and late pregnancy was positive and significant for gestation length, fetal cotyledon weight and birthweight, but notably weight measures in late pregnancy are confounded by the weight of the gravid uterus.

\section{Discussion}

\section{Optimum pregnancy outcome in young adolescent sheep}

The nutritional management of the control-fed adolescents provided the optimum benchmark for gestation length, placental growth and lamb birthweight and was key to the approach used to define 

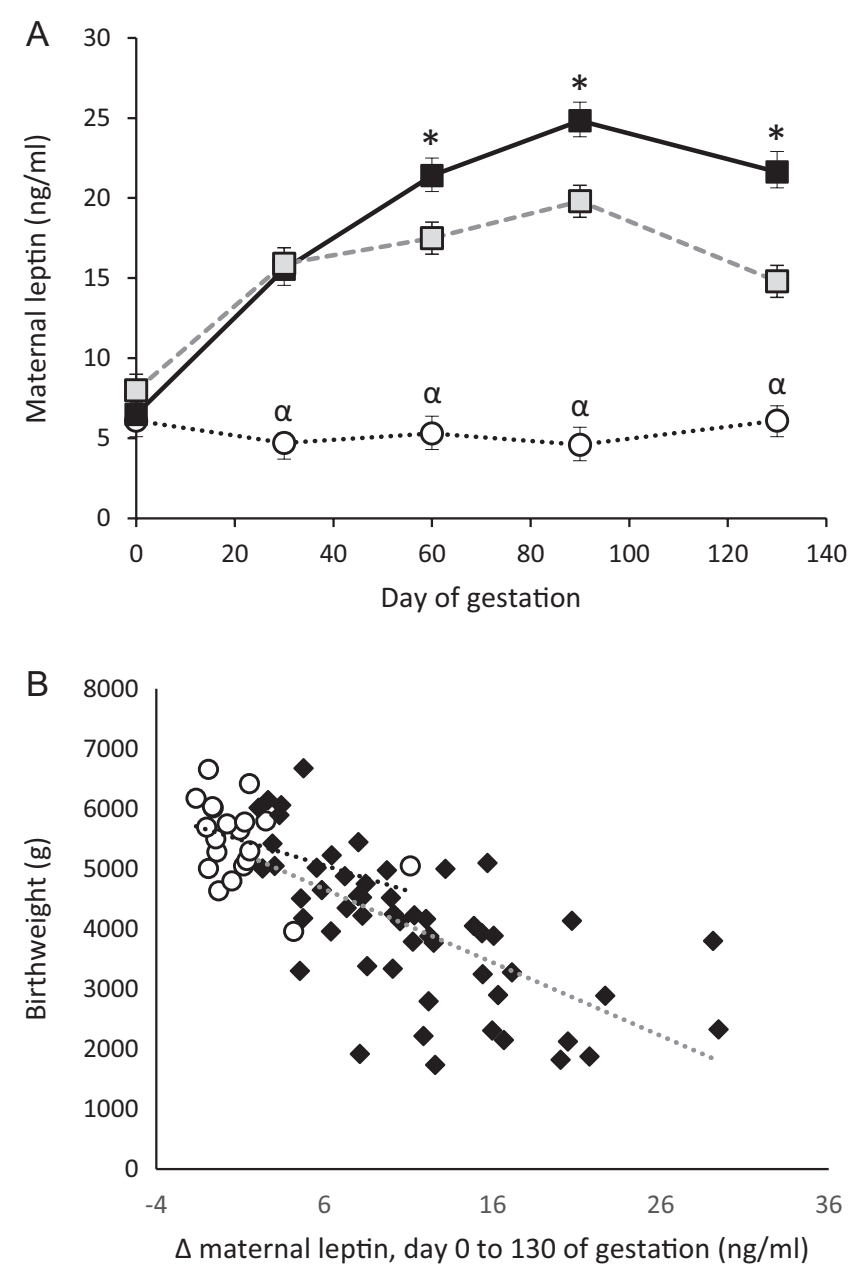

Figure 2 Maternal plasma leptin concentrations throughout gestation in control (open circles, $n=18$ ) and overnourished pregnancies categorised as FGR (black squares, $n=29$ ) or non-FGR (grey squares, $n=26$ ) based on lamb birthweight (A), and the relationship between the change in maternal leptin concentrations between days 0 and 130 of gestation and lamb birthweight (B). For (A) stage of gestation, prenatal growth category and their interaction were significant $P<$ 0.001 , control differed from both overnourished groups from days 30 to 130 inclusive $(\alpha)$ and FGR differed from non-FGR at 60,90 and 130 days gestation $(*), P<0.05$. For (B) $r=-0.455, P=0.05$ for control (open circles), and $r=-0.643, P<0.001$ for overnourished pregnancies (black diamonds).

compromised pregnancies in the present study. By design all ewes gestated a singleton from the outset and a GWG of $75 \mathrm{~g}$ per day during the first two-thirds of gestation facilitated a small amount of maternal growth, while stepwise increases in dietary intake during the final-third of pregnancy met fetal nutrient requirement while maintaining maternal adiposity, and an average birthweight of $5.4 \mathrm{~kg}$ was achieved. This birthweight was comparable to that reported for control-fed adolescents of similar age/weight at conception and housed individually throughout pregnancy following natural conception at a synchronised oestrus ( 5.1 and $5.3 \mathrm{~kg}$ : Peel et al. 2012), and exceeded that achieved in adolescents spontaneously ovulating at puberty and managed at pasture (range in average singleton birthweight per study, 4.2-4.6 kg: Mulvaney et al. 2010a, Corner et al. 2013, Pettigrew et al. 2019). It also compares favourably with the average singleton birthweight in a large cohort of mature multiparous ewes housed to facilitate appropriate nutritional management in the final-third of gestation (5.5 kg, $n=667$ : Gardner et al. 2007). These studies involve a variety of genotypes but importantly our optimum birthweight in control-fed adolescents also matches that achieved in mature primiparous ewes of the same genotype, housed and nutritionally managed in an identical manner (5.2 kg: Wallace et al. 2005). The latter study also uniquely provides a comparison for optimum placental growth, and there is striking similarity in both placental weight (477 vs $442 \mathrm{~g}$ ) and total fetal cotyledon weight (156 vs $146 \mathrm{~g}$ ) at delivery in mature compared with adolescent pregnancies.

\section{Maternal anthropometry and the extent of prenatal growth compromise in growing adolescents}

In contrast to the optimally fed controls, overnourishing adolescents of equivalent age throughout gestation promotes continued maternal growth at the expense of the conceptus. The retrospective analysis of this entire cohort had sufficient power to examine the anthropometric antecedents of FGR within the overnourished group and reveals maternal differences at the point of embryo transfer (conception), and during early pregnancy. The recipients that conceived and went on to have an FGR pregnancy were both lighter and leaner at conception than the contemporaneous nonFGR group. These differences were small (but significant) and are commensurate with the poorer reproductive performance of lighter adolescent (ewe) lambs in terms of reaching natural puberty, conception rate, litter size and offspring weight at weaning (reviewed by Kenyon et al. 2014). Although even the smallest of the adolescents studied herein were considered relatively well grown for their age, we have previously reported a decrease in average birthweight of $\sim 500 \mathrm{~g}$ in adolescents who were deliberately selected for breeding based on a much larger differential in baseline weight $(10 \mathrm{~kg})$ and adiposity (0.5 units) than observed here (Wallace et al. 2010). Within the overnourished animals in the current dataset the most striking difference between pregnancies destined to become compromised was a relatively high GWG. On a group basis this divergence was specific to the first third of gestation and applied similarly to pregnancies categorised on the basis of placental mass, lamb birthweight and very preterm delivery (i.e. average differential of 32-38 g per day). Irrespective of degree of prenatal compromise the GWG reported here greatly exceeds that reported in overnourished animals in both pasture-based (Morris et al. 2005, Kenyon et al. 2008, Mulvaney et al. 2008, 2010b), and individually housed 
adolescent studies (Meyer et al. 2010, Peel et al. 2012), and may in part explain why they fail to report a negative impact on birthweight. None of the aforementioned studies report placental weight at delivery. Herein the implication is a broad threshold of high GWG above which pregnancies are widely compromised but it is noteworthy that the non-FGR pregnancies still have a statistically lower placental weight and lamb birthweight than the optimally nourished controls. We have long contended that impaired placental growth is the root cause of poor pregnancy outcome in rapidly growing adolescents. The relative importance of the first-third of gestation as highlighted here is in agreement with previous observations of reduced cellular proliferation rates within both the maternal caruncle and fetal cotyledon components of the placenta (Rensick et al. 2008), and with attenuated capillary vessel size and density within the fetal cotyledon (Redmer et al. 2009), both of which were evident at day 50 of gestation when compared with optimally fed controls. As placental weight per se is not generally significantly perturbed in overnourished dams until $0.7 \times$ gestation the likely severity of placental and/or fetal growth-restriction in individual pregnancies terminated at $0.34 \times$ gestation is impossible to predict. However, it is notable that when pregnancies were interrupted in late gestation (day 131) placental vascularity in the fetal cotyledon of those with marked FGR was lower than the non-FGR group (Carr et al. 2016). Moreover, given that we have identified that rapid GWG during early pregnancy is key to the severity of prenatal growth-restriction it is understandable that studies in other laboratories that began overfeeding adolescents at day 50 of gestation did not influence placental weight and had a very modest effect on birthweight ( $9 \%$ reduction) in a mixed population of single and twin pregnancies (Swanson et al. 2008).

As outlined in the 'Introduction' section, it is the youngest girls who are at greatest risk of adverse outcomes including preeclampsia, preterm delivery, and low birthweight, and biological immaturity of the reproductive tract is proposed as a key driver of the presumed underlying placental dysfunction. Brosens et al. (2017) propose that the immature uterus requires exposure to regular ovulatory menstrual cycles to prepare for appropriate trophoblast invasion in early gestation. This hypothesis has merit given that the animals studied here were considered peripubertal and overnourished growing dams specifically have delayed and reduced appearance of placental lactogen and pregnancy specific protein-B in the maternal circulation commensurate with impaired trophoblast cell migration (Wallace et al. 1997b, Lea et al. 2007). No attempt was made to define whether puberty had occurred prior to the start of oestrus synchronisation in the present study as oestrus without ovulation, and conversely ovulation without oestrus, is commonplace at the beginning of the first breeding season (Dyrmundsson 1981, Da Silva et al. 2001). The animals were considered peripubertal as there was variable evidence of a prior ovarian cycle (corpus albicans) when the ovary was visualised to confirm ovulation rate and the viability of the corpus luteum at the time of embryo transfer. This was not a factor considered in the allocation of animals to nutritional treatment which was instead based on weight, adiposity and ovulation rate in animals of equivalent chronological age. Nevertheless, it is clear that the combination of biological immaturity and rapid GWG during the period of trophoblast proliferation makes these young still-growing adolescents vulnerable to placental insufficiency, leading to FGR. There is a lack of direct data linking differences in maternal growthvelocity, placental growth and pregnancy outcome in human adolescents but high total GWG above recommended levels for individual pre-pregnancy BMI categories have been linked to a two-fold greater risk of low birthweight $(<2500 \mathrm{~g}): 40 \%$ of the adolescent participants were $12-15$ years old and likely to be still-growing (Sámano et al. 2018). Trimester-specific weight-gains were not reported in the latter study but the concept that weight-gain during the first trimester plays an important role in setting the fetal-placental growth trajectory (albeit in a different direction) is supported by studies in adult women (Broskey et al. 2017, Retnakaran et al. 2018).

\section{Maternal leptin as an index of fat accrual and predictor of adverse pregnancy outcome}

The early divergence in maternal leptin concentrations between control-fed and overnourished adolescents parallels the wide nutritionally mediated differences in maternal growth rate and fat deposition, and confirms a previous report (Thomas et al. 2001). Notably leptin levels did not change between conception and late pregnancy in the control group indicating that the nutritional approach to maintain maternal fat stores at a consistent level and thereby meet the evolving fetal nutrient requirement throughout gestation was successfully achieved. In the human, leptin produced by the placenta contributes to higher maternal leptin concentrations as pregnancy progresses and dysregulation of placental leptin is implicated in the aetiology of a number of pregnancy complications including FGR (Kochhar et al. 2020). In contrast the ovine placenta does not express significant amounts of leptin mRNA and is unlikely to make a major contribution to peripheral leptin concentrations (Thomas et al. 2001, O'Conner et al. 2007). The lack of change in maternal leptin in the control group with the greatest placental mass herein further argues against a role for placental leptin involvement in ovine fetal growth. Here we demonstrate for the first time that changes in leptin concentrations beginning during the first-third of pregnancy are a sensitive biomarker of more subtle differences in whole body fat accrual 
within rapidly growing adolescents exposed to an equivalent nutritional manipulation, and are highly predictive of the degree of prenatal growth-restriction and prematurity recorded at delivery. For this subgroup of the main cohort a greater change in subjective external (subcutaneous) fat score specific to the firstthird of gestation was also negatively associated with pregnancy outcome. Thus for this retrospective cohort overall the emerging picture within the overnourished group is that adolescents with the greatest GWG and/ or fat accrual in early pregnancy were more likely to experience placental growth insufficiency leading to reduced fetal growth-velocity and low birthweight. In human adolescents delta leptin between study entry at 17 and 28 weeks gestation was similarly high in girls who continued to grow and associated with greater weight-gain and skinfold thicknesses (Scholl et al. 2000). Moreover, girls in the upper quartile for leptin had a sixfold higher risk of FGR, and although placental weight at delivery was not reported, alterations in umbilical artery Doppler waveforms consistent with reduced blood flow and thereby attenuated fetal nutrient supply have been reported for this specific adolescent population (Scholl et al. 1997). In humans as in sheep, this alteration in the hierarchy of nutrient partitioning is most likely confined to very young and gynaecologically immature adolescents as similarly high GWG, skinfold increases and leptin concentrations in older slow-growing compared with non-growing adolescents (median age 17.8 years, gynaecological age 5 years) was positively associated with birthweight (Jones et al. 2010) and did not impact growth or morphology of the placenta (Hayward et al. 2011).

\section{Maternal anthropometry and preterm delivery}

The putative mechanisms underlying the reduction in gestation length in overnourished compared with optimally fed control animals have been discussed previously and likely includes attenuated placental reproductive steroid secretion and precocious development and function of the fetal adrenals (Wallace et al. 2004). The retrospective analysis presented here involved sufficient pregnancies to define two categories of early delivery, namely preterm and very preterm, and accordingly it was the FGR pregnancies that were most severely perturbed with $27 \%$ of lambs born at or before day 139 of gestation. Moreover these very preterm deliveries were preceded by greater GWG (entire cohort) or fat accrual (subgroup) during the first-half of pregnancy compared with those delivered at term, again indicating the importance of nutrient partitioning priorities established during early pregnancy. Similarly, in the two identical trials of Peel et al. (2012) involving exposing singleton bearing adolescents to ad libitum intakes throughout pregnancy the trial where maternal weight and adiposity diverged earlier, and to a greater extent, was associated with a 5-day reduction in gestation length similar in magnitude to that reported here. High GWG, greater fat accrual and continued maternal growth are not directly associated with early delivery in human adolescents (Scholl et al. 1997, Jones et al. 2010) but in young girls $<16$ years, a low but not a higher gynaecological age $(\leq$ or $>2$ years, respectively) is associated with a two-fold greater risk of spontaneous preterm delivery compared with adult women (Hediger et al. 1997), and reinforces the vulnerability of biologically immature adolescents to poor outcomes.

In humans, fetal sex influences a number of pregnancy outcomes with males being disadvantaged with respect to increased risk of preterm delivery and term-SGA birth following natural conception (Al-Qaraghouli \& Fang, 2017), but advantaged in terms of their representation in newborns after blastocyst transfer following assisted conception (Ding et al. 2018). However, in the present study, we found no imbalance in the sex ratio of lambs following embryo transfer in the study overall and no difference in the sex ratio within early delivery or prenatal growth categories. Males were in fact heavier than females in the control, non-FGR and FGR groups, and the differential in birthweight between sexes in the control and overnourished groups (316 and 326 g, respectively) closely aligns with the extra $363 \mathrm{~g}$ attributed to male sex in a large cohort of multiparous ewes with variable litter size (Gardner et al. 2007).

In summary, we deliberately established a major competition for nutrients between maternal and conceptus growth in biologically immature adolescent sheep to replicate the scenario observed in still-growing very young girls. This retrospective analysis reveals that the degree of premature delivery and prenatal growthrestriction within these overnourished pregnancies is dependent on high GWG and fat accrual during early pregnancy. This coincides with the main period of placental growth and a key phase of vascular development, which in turn lays the haemodynamic foundations for nutrient supply to the fetus. Reduced placental nutrient supply has been implicated in the pathway to reduced fetal growth in adolescents who have not achieved their predicted height based on the height of their parents (Frisancho et al. 1985), but there is a paucity of placental data in relation to measured growth in gynaecologically immature human adolescents, and this should be a focus in future prospective studies.

\section{Declaration of interest}

The authors declare that there is no conflict of interest that could be perceived as prejudicing the impartiality of the research reported. 


\section{Funding}

This work was funded by the Scottish Government's Rural and Environment Science and Analytical Services Division.

\section{Author contribution statement}

J W developed the animal model, performed experiments, analysed the data and wrote the paper. R A and J M performed experiments and conducted the laboratory analysis.

\section{Acknowledgements}

Dr Graham Horgan (Biomathematics and Statistics Scotland) provided statistical advice and Dr Clare Adam gifted the leptin antibody.

\section{References}

Adam CL, Findlay PA, Aitken RP, Milne JS \& Wallace JM 2011 Influence of birth weight, sex, age and adiposity on central leptin and insulin sensitivity in young growing sheep, as indicated by changes in voluntary food intake. Proceedings of the Nutrition Society 70 E382. (https://doi. org/10.1017/S0029665111004678)

Al-Qaraghouli M \& Fang YMV 2017 Effect of fetal sex on maternal and obstetric outcomes. Frontiers in Pediatrics 5 144. (https://doi. org/10.3389/fped.2017.00144)

Azevedo WF, Diniz MB, Fonseca ES, Azevedo LM \& Evangelista CB 2015 Complications in adolescent pregnancy: systematic review of the literature. Einstein 13 618-626. (https://doi.org/10.1590/S167945082015RW3127)

Beck NFG, Davies MCG \& Davies B 1996 A comparison of ovulation rate and late embryonic mortality in ewe lambs and ewes and the role of late embryo loss in ewe lamb subfertility. Animal Science 62 79-83. (https:// doi.org/10.1017/S135772980001434X)

Brosens I, Muter J, Gargett CE, Puttemans P, Benagiano G \& Brosens JJ 2017 The impact of uterine immaturity on obstetrical syndromes during adolescence. American Journal of Obstetrics and Gynecology 217 546-555. (https://doi.org/10.1016/j.ajog.2017.05.059)

Broskey NT, Wang P, Li N, Leng J, Li W, Wang L, Gilmore LA, Hu G \& Redman LM 2017 Early pregnancy weight gain exerts the strongest effect on birth weight, posing a critical time to prevent childhood obesity. Obesity 25 1569-1576. (https://doi.org/10.1002/oby.21878)

Carr DJ, David AL, Aitken RP, Milne JS, Borowicz PP, Wallace JM \& Redmer DA 2016 Placental vascularity and markers of angiogenesis in relation to prenatal growth status in overnourished adolescent ewes. Placenta 46 79-86. (https://doi.org/10.1016/j.placenta.2016.08.076)

Conde-Agudelo A, Belizán JM \& Lammers C 2005 Maternal-perinatal morbidity and mortality associated with adolescent pregnancy in Latin America: cross-sectional study. American Journal of Obstetrics and Gynecology 192 342-349. (https://doi.org/10.1016/j.ajog.2004.10.593)

Corner RA, Mulvaney FJ, Morris ST, West DM, Morel PCH \& Kenyon PR 2013 A comparison of the reproductive performance of ewe lambs and mature ewes. Small Ruminant Research 114 126-133. (https://doi. org/10.1016/j.smallrumres.2013.05.018)

Da Silva P, Aitken RP, Rhind SM, Racey PA \& Wallace JM 2001 Influence of placentally mediated fetal growth restriction on the onset of puberty in male and female lambs. Reproduction 122 375-383. (https://doi. org/10.1530/rep.0.1220375)

Ding J, Yin T, Zhang Y, Zhou D \& Yang J 2018 The effect of blastocyst transfer on newborn sex ratio and monozygotic twinning rate: an updated systematic review and meta-analysis. Reproductive Biomedicine Online 37 292-303. (https://doi.org/10.1016/j.rbmo.2018.05.015)

Dyrmundsson OR 1981 Natural factors affecting puberty and reproductive performance in ewe lambs: a review. Livestock Production Science $\mathbf{8}$ $55-65$.
Edwards SJ, Smaill B, O'Connell AR, Johnstone PD, Stevens DR, Quirke LD, Farquhar PA \& Juengel JL 2016 Reduced ovulation rate, failure to be mated and fertilization failure/embryo loss are the underlying causes of poor reproductive performance in juvenile ewes. Animal Reproduction Science 167 125-132. (https://doi.org/10.1016/j.anireprosci.2016.02.017)

Ehrhardt RA \& Bell AW 1995 Growth and metabolism of the ovine placenta during mid-gestation. Placenta 16 727-741. (https://doi. org/10.1016/0143-4004(95)90016-0)

Frisancho AR, Matos J, Leonard WR \& Yaroch LA 1985 Developmental and nutritional determinants of pregnancy outcome among teenagers. American Journal of Physical Anthropology 66 247-261. (https://doi. org/10.1002/ajpa.1330660302)

Ganchimeg T, Ota E, Morisaki N, Laopaiboon M, Lumbiganon P, Zhang J, Yamdamsuren B, Temmerman M, Say L, Tuncalp Ö et al. 2014 Pregnancy and childbirth outcomes among adolescent mothers: a World Health Organization multicountry study. BJOG 121 (Supplement 1) 40-48. (https://doi.org/10.1111/1471-0528.12630)

Gardner DS, Buttery PJ, Daniel Z \& Symonds ME 2007 Factors affecting birth weight in sheep: maternal environment. Reproduction 133 297-307. (https://doi.org/10.1530/REP-06-0042)

Hayward CE, Greenwood SL, Sibley CP, Baker PN \& Jones RL 2011 Effect of young maternal age and skeletal growth on placental growth and development. Placenta 32 990-998. (https://doi.org/10.1016/j. placenta.2011.09.016)

Hediger ML, Scholl TO, Schall JI \& Krueger PM 1997 Young maternal age and preterm labor. Annals of Epidemiology 7 400-406. (https://doi. org/10.1016/s1047-2797(97)00046-x)

Jones RL, Cederberg HMS, Wheeler SJ, Poston L, Hutchinson CJ, Seed PT, Oliver RL \& Baker PN 2010 Relationship between maternal growth, infant birthweight and nutrient partitioning in teenage pregnancies. BJOG 117 200-211. (https://doi.org/10.1111/j.1471-0528.2009.02371.x)

Kenyon PR, Morris ST \& West DM 2008 Effects of nutrition during pregnancy on hogget pregnancy outcome and birthweight and liveweights of lambs. New Zealand Journal of Agricultural Research $\mathbf{5 1}$ 77-83. (https://doi.org/10.1080/00288230809510437)

Kenyon PR, Thompson AN \& Morris ST 2014 Breeding ewe lambs successfully to improve lifetime performance. Small Ruminant Research 118 2-15. (https://doi.org/10.1016/j.smallrumres.2013.12.022)

Kochhar P, Manikandan C, Ravikumar G, Dwarkanath P, Sheela CN, George S, Thomas A, Crasta J, Thomas T, Kurpad AV et al. 2020 Placental expression of leptin: fetal sex-independent relation with human placental growth. European Journal of Clinical Nutrition 74 1603-1612. (https:// doi.org/10.1038/s41430-020-0649-9)

Kozuki N, Lee AC, Silveira MF, Sania A, Vogel JP, Adair L, Barros F, Caulfield LE, Christian P, Fawzi W et al. 2013 The associations of parity and maternal age with small-for-gestational-age, preterm, and neonatal and infant mortality: a meta-analysis. BMC Public Health 13 (Supplement 3) S2. (https://doi.org/10.1186/1471-2458-13-S3-S2)

Lea RG, Wooding P, Stewart I, Hannah LT, Morton S, Wallace K, Aitken RP, Milne JS, Regnault TR, Anthony RV et al. 2007 The expression of ovine placental lactogen, Star and progesterone-associated steroidogenic enzymes in placentae of overnourished growing adolescent ewes. Reproduction 133 785-796. (https://doi.org/10.1530/REP-06-0294)

Leppälahti S, Gissler M, Mentula M \& Heikinheimo O 2013 Is teenage pregnancy an obstetric risk in a welfare society? A population-based study in Finland, from 2006 to 2011. BMJ Open 3 e003225. (https://doi. org/10.1136/bmjopen-2013-003225)

Malabarey OT, Balayla J, Klam SL, Shrim A \& Abenhaim HA 2012 Pregnancies in young adolescent mothers: a population-based study on 37 million births. Journal of Pediatric and Adolescent Gynecology 25 98-102. (https://doi.org/10.1016/j.jpag.2011.09.004)

Marie M, Findlay PA, Thomas L \& Adam CL 2001 Daily patterns of plasma leptin in sheep: effects of photoperiod and food intake. Journal of Endocrinology 170 277-286. (https://doi.org/10.1677/joe.0.1700277)

Marvin-Dowle K \& Soltani H 2020 A comparison of neonatal outcomes between adolescent and adult mothers in developed countries: a systematic review and meta-analysis. European Journal of Obstetrics and Gynecology and Reproductive Biology 6 100109. (https://doi. org/10.1016/j.eurox.2020.100109)

McMillan WH \& McDonald MF 1985 Survival of fertilised ova from ewe lambs and adult ewes in the uteri of ewe lambs. Animal Reproduction Science 8 235-240. (https://doi.org/10.1016/0378-4320(85)90028-4) 
Meyer AM, Reed JI, Neville TL, Taylor JB, Hammer CJ, Reynolds LP, Redmer DA, Vonnahme KA \& Caton JS 2010 Effects of plane of nutrition and selenium supply during gestation on ewe and neonatal offspring performance, body composition, and serum selenium. Journal of Animal Science 88 1786-1800. (https://doi.org/10.2527/jas.20092435)

Miller DW, Bennett EJ, Harrison JL, Anderson F \& Adam CL 2018 Dualenergy X-ray absorptiometry scans accurately predict differing body fat content in live sheep. Journal of Animal Science and Biotechnology 980. (https://doi.org/10.1186/s40104-018-0295-4)

Morris ST, Kenyon PR \& West DM 2005 Effect of hogget nutrition in pregnancy on lamb birth weight and survival to weaning. New Zealand Journal of Agricultural Research 48 165-175. (https://doi.org/10.1080/0 0288233.2005.9513647)

Mulvaney FJ, Kenyon PR, Morris ST \& West DM 2008 Ewe lamb nutrition during pregnancy affects pregnancy outcome. Australian Journal of Experimental Agriculture 48 1085-1089. (https://doi.org/10.1071/ EA08078)

Mulvaney FJ, Morris ST, Kenyon PR, West DM \& Morel PCH 2010a Effect of liveweight at the start of the breeding period and liveweight gain during the breeding period and pregnancy on reproductive performance of hoggets and the liveweight of their lambs. New Zealand Journal of Agricultural Research 53 355-364. (https://doi.org/10.1080/00288233. 2010.504527)

Mulvaney FJ, Morris ST, Kenyon PR, West DM \& Morel PCH $2010 b$ Effect of nutrition around the time of breeding and during pregnancy on yearling live weight change, pregnancy loss and live weight and survival of their offspring. Proceedings of the New Zealand Society of Animal Production 70 91-95.

Neal S, Mahendra S, Bose K, Camacho AV, Mathai M, Nave A, Santan F \& Matthews Z 2016 The causes of maternal mortality in adolescents in low and middle income countries: a systematic review of the literature. $B M C$ Pregnancy and Childbirth 16 352. (https://doi.org/10.1186/s12884-0161120-8)

Neal S, Channon AA \& Chintsanya J 2018 The impact of young maternal age at birth on neonatal mortality: evidence from 45 low and middle income countries. PLoS ONE 13 e0195731. (https://doi.org/10.1371/ journal.pone.0195731)

O'Connor DM, Blache D, Hoggard N, Brookes E, Wooding FB, Fowden AL \& Forhead AJ 2007 Developmental control of plasma leptin and adipose leptin messenger ribonucleic acid in the ovine fetus during late gestation: role of glucocorticoids and thyroid hormones. Endocrinology 148 3750-3757. (https://doi.org/10.1210/en.2007-0310)

Paul P 2018 Maternal age at marriage and adverse pregnancy outcomes: findings from the India Human Development Survey, 2011-2012. Journal of Pediatric and Adolescent Gynecology 31 620-624. (https:// doi.org/10.1016/j.jpag.2018.08.004)

Peel RK, Eckerle GJ \& Anthony RV 2012 Effects of overfeeding naturallymated adolescent ewes on maternal, fetal, and postnatal lamb growth. Journal of Animal Science 90 3698-3708. (https://doi.org/10.2527/ jas.2012-5140)

Pettigrew EJ, Hickson RE, Morris ST, Lopez-Villalobos N, Pain SJ, Kenyon PR \& Blair HT 2019 The effects of birth rank (single or twin) and dam age on the lifetime productive performance of female dual purpose sheep (Ovis aries) offspring in New Zealand. PLoS ONE 14 e0214021. (https://doi.org/10.1371/journal.pone.0214021)

Quirke JF \& Hanrahan JP 1977 Comparison of the survival in the uteri of adult ewes of cleaved ova from adult ewes and ewe lambs. Journal of Reproduction and Fertility 51 487-489. (https://doi.org/10.1530/ jrf.0.0510487)

Redmer DA, Luther JS, Milne JS, Aitken RP, Johnson ML, Borowicz PP, Borowicz MA, Reynolds LP \& Wallace JM 2009 Fetoplacental growth and vascular development in overnourished adolescent sheep at day 50, 90 and 130 of gestation. Reproduction 137 749-757. (https://doi. org/10.1530/REP-08-0516)

Rensick L, Aitken R, Milne J, Borowicz P, Scheaffer A, Carlson D, Reynolds L, Wallace J \& Redmer D 2008 Influence of maternal nutrition on cellular proliferation rates of placental tissues in singleton ovine adolescent pregnancies at day 50 and 75 of gestation. Journal of Animal Science 86 (Supplement 3) 291.

Retnakaran R, Wen SW, Tan H, Zhou S, Ye C, Shen M, Smith GN \& Walker MC 2018 Association of timing of weight gain in pregnancy with infant birth weight. JAMA Pediatrics 172 136-142. (https://doi. org/10.1001/jamapediatrics.2017.4016)

Russel AJF, Doney JM \& Gunn RG 1969 Subjective assessment of body fat in live sheep. Journal of Agricultural Science 72 451-454. (https://doi. org/10.1017/S0021859600024874)

Salihu HM, Sharma PP, Ekundayo OJ, Kristensen S, Badewa AP, Kirby RS \& Alexander GR 2006 Childhood pregnancy (10-14 years old) and risk of stillbirth in singletons and twins. Journal of Pediatrics 148 522-526. (https://doi.org/10.1016/j.jpeds.2005.11.018)

Sámano R, Chico-Barba G, Martinez-Rojano H, Godinez E, RodriguezVentura AL, Ávila-Koury G \& Aguillar-Sánchez K 2018 Pre-pregnancy body mass index classification and gestational weight gain on neonatal outcomes in adolescent mothers: a follow-up study. PLOS ONE 13 e0200361. (https://doi.org/10.1371/journal.pone.0200361)

Scholl TO, Hediger ML, Schall JI, Khoo CS \& Fischer RL 1994 Maternal growth during pregnancy and the competition for nutrients. American Journal of Clinical Nutrition 60 183-188. (https://doi.org/10.1093/ ajcn/60.2.183)

Scholl TO, Hediger ML \& Schall JI 1997 Maternal growth and fetal growth: pregnancy course and outcome in the Camden study. Annals of the New York Academy of Sciences 817 292-301. (https://doi. org/10.1111/j.1749-6632.1997.tb48215.x)

Scholl TO, Stein TP \& Smith WK 2000 Leptin and maternal growth during adolescent pregnancy. American Journal of Clinical Nutrition 72 1542-1547. (https://doi.org/10.1093/ajcn/72.6.1542)

Swanson TJ, Hammer CJ, Luther JS, Carlson DB, Taylor JB, Redmer DA, Neville TL, Reed JJ, Reynolds LP, Caton JS et al. 2008 Effects of gestational plane of nutrition and selenium supplementation on mammary development and colostrum quality in pregnant ewe lambs. Journal of Animal Science 86 2415-2423. (https://doi.org/10.2527/ jas.2008-0996)

Thomas L, Wallace JM, Aitken RP, Mercer JG, Trayhurn P \& Hoggard N 2001 Circulating leptin during ovine pregnancy in relation to maternal nutrition, body composition and pregnancy outcome. Journal of Endocrinology 169 465-476. (https://doi.org/10.1677/joe.0.1690465)

Torvie AJ, Callegari LS, Schiff MA \& Debiec KE 2015 Labour and delivery outcomes among young adolescents. American Journal of Obstetrics and Gynecology 213 95.e1-95.e8. (https://doi.org/10.1016/j. ajog.2015.04.024)

Wallace JM, Aitken RP \& Cheyne MA 1996 Nutrient partitioning and fetal growth in rapidly growing adolescent ewes. Journal of Reproduction and Fertility 107 183-190. (https://doi.org/10.1530/jrf.0.1070183)

Wallace JM, DaSilva P, Aitken RP \& Cruickshank MA 1997a Maternal endocrine status in relation to pregnancy outcome in rapidly growing adolescent sheep. Journal of Endocrinology 155 359-368. (https://doi. org/10.1677/joe.0.1550359)

Wallace JM, Aitken RP, Cheyne MA \& Humblot P 1997b Pregnancyspecific protein $B$ and progesterone concentrations in relation to nutritional regimen, placental mass and pregnancy outcome in growing adolescent ewes carrying singleton fetuses. Journal of Reproduction and Fertility 109 53-58. (https://doi.org/10.1530/jrf.0.1090053)

Wallace JM, Bourke DA, Aitken RP, Leitch N \& Hay WW Jr 2002 Blood flows and nutrient uptakes in growth-restricted pregnancies induced by overnourishing adolescent sheep. American Journal of Physiology: Regulatory, Integrative and Comparative Physiology 282 R1027-R1036. (https://doi.org/10.1152/ajpregu.00465.2001)

Wallace JM, Aitken RP, Milne JS \& Hay Jr WW 2004 Nutritionally mediated placental growth restriction in the growing adolescent: consequences for the fetus. Biology of Reproduction 71 1055-1062. (https://doi. org/10.1095/biolreprod.104.030965)

Wallace JM, Milne JS \& Aitken RP 2005 The effect of overnourishing singleton-bearing adult ewes on nutrient partitioning to the gravid uterus. British Journal of Nutrition 94 533-539. (https://doi.org/10.1079/ bjn20041398)

Wallace JM, Milne JS, Redmer DA \& Aitken RP 2006 Effect of diet composition on pregnancy outcome in overnourished rapidly growing adolescent sheep. British Journal of Nutrition 96 1060-1068. (https://doi. org/10.1017/bjn20061979)

Wallace JM, Milne JS, Matsuzaki M \& Aitken RP 2008 Serial measurement of uterine blood flow from mid to late gestation in growth restricted pregnancies induced by overnourishing adolescent sheep dams. Placenta 29 718-724. (https://doi.org/10.1016/j.placenta.2008.05.006) 
Wallace JM, Milne JS \& Aitken RP 2010 Effect of weight and adiposity at conception and wide variations in gestational dietary intake on pregnancy outcome and early postnatal performance in young adolescent sheep. Biology of Reproduction 82 320-330. (https://doi. org/10.1095/biolreprod.109.080069)

Wallace JM, Milne JS, Green LR \& Aitken RP 2011 Postnatal hypothalamicpituitary-adrenal function in sheep is influenced by age and sex, but not by prenatal growth restriction. Reproduction, Fertility and Development 23 275-284. (https://doi.org/10.1071/RD10103)

Wallace JM, Milne JS, Adam CL \& Aitken RP 2012 Adverse metabolic phenotype in low-birth-weight lambs and its modification by postnatal nutrition. British Journal of Nutrition 107 510-522. (https://doi. org/10.1017/S0007114511003175)

Wallace JM, Milne JS, Aitken RP \& Adam CL 2014 Influence of birth weight and gender on lipid status and adipose tissue gene expression in lambs. Journal of Molecular Endocrinology 53 131-144. (https://doi. org/10.1530/JME-14-0123)

Wallace JM, Milne JS, Aitken RP, Horgan GW \& Adam CL 2018 Ovine prenatal growth restriction impacts glucose metabolism and body composition throughout life in both sexes. Reproduction 156 103-119. (https://doi.org/10.1530/REP-18-0048)

Wallace JM, Milne JS, Aitken BW, Aitken RP \& Adam CL 2020 Ovine prenatal growth-restriction and sex influence fetal adipose tissue phenotype and impact postnatal lipid metabolism and adiposity in vivo from birth until adulthood. PLOS ONE 15 e0228732. (https://doi. org/10.1371/journal.pone.0228732)

Weng YH, Yang CY \& Chiu YW 2014 Risk assessment of adverse birth outcomes in relation to maternal age. PLOS ONE 9 e114843. (https://doi. org/10.1371/journal.pone.0114843)

Received 25 September 2020

First decision 10 November 2020

Revised manuscript received 24 November 2020

Accepted 1 December 2020 